\title{
Estimativa da geração de resíduos da construção civil
}

\section{Estimation of construction and demolition waste generation}

Data de entrada: 22/10/2018

Data de aprovação: 06/03/2020
Daniel Guimarães $^{1 *}$ | Fabiana Fiore ${ }^{2}$

ORCID ID

Guimarães D (D) https://orcid.org/0000-0002-5951-751X
DOI: https://doi.org/10.36659/dae.2021.055

Fiore F (D) http://orcid.org/0000-0002-2430-8240

\section{Resumo}

A poluição difusa decorrente da disposição inadequada dos resíduos da construção civil (RCC) ainda é realidade nos territórios brasileiros. A maioria dos municípios sequer possui informações sobre a massa total que é gerada e disposta em seu território. Essa ausência de dados conflita com a obrigatoriedade legal de serem estabelecidas, pelos municípios, as diretrizes locais para o manejo adequado desses resíduos. Em vista disso, este trabalho apresenta o desenvolvimento de dois modelos matemáticos de aproximação estatística, em diferentes escalas territoriais, por meio dos quais é possível estimar a geração de RCC em municípios do estado de São Paulo. Os modelos propostos foram aplicados a 11 municípios do estado de São Paulo e os resultados indicaram que a geração de RCC, para essa unidade da federação, aumenta tanto em função do número de habitantes como em função de suas rendas.

Palavras-chave: Resíduos sólidos. Construção civil. Gestão pública. Geração de RCC.

\section{Abstract}

The diffuse pollution, due to inadequate waste disposal, is still a reality in Brazilian territory. Most municipalities do not have information referring to the total mass of RCCs generated and disposal in their territory. The absence of actual data conflicts with the legal obligation to be established, by the municipalities, local guidelines for correctly managing this type of waste. In such context, this work presents the development of two mathematical models for statistical estimation, in different territorial scales, through which it is possible to estimate amounts of RCC generation in São Paulo state municipalities. The proposed models were applied to 11 municipalities in the São Paulo state. Results indicated that the generation of RCC in São Paulo region increases both as a function of inhabitants quantity and as a function of annual average incomes.

Keywords: Solid waste. Civil construction. Public management. RCC generation.

\footnotetext{
${ }^{1}$ Sabesp - São José dos Campos - São Paulo - Brasil.

2 Universidade Estadual Paulista "Júlio de Mesquita Filho" - São José dos Campos - São Paulo - Brasil.

*Autor correspondente: damguimaraesasabesp.com.br.
} 


\section{INTRODUÇÃO}

Em todo o território brasileiro, atividades relacionadas à construção civil estão entre as que mais geram resíduos sólidos. A preocupação decorrente dessa geração não se limita ao volume de resíduos gerados, mas estende-se para o lançamento irregular em terrenos baldios, mananciais e áreas de proteção ambiental, pois geram significativos impactos ambientais e econômicos (KUSUNOKI, GOBBI e CHARVET, 2020; PAZ, LAFAYETTE e SOBRAL, 2018; SAMPAIO et al., 2015). Se por um lado as ações municipais de gestão têm se revelado precárias e incapazes de dar tratamentos adequados a todos os resíduos gerados, por outro, os elevados requisitos de qualidade explicitados nos instrumentos legais, vigentes no país, abrangem de forma integrada e sistêmica toda a cadeia produtiva e o ciclo de vida dos materiais (CONAMA, 2002; BRASIL, 2010).

A viabilidade técnica de novos usos dos RCC, inclusive para a própria atividade de construção civil, é reconhecida por pesquisas e aplicações pontuais no país e subsidiaram a publicação de normas regulamentadoras, com vistas ao uso benéfico do material (LIMA e CABRAL, 2013; LOCH, STOCKER e BERTOLINI, 2019; ABNT, 2004 a, b). Porém, considerados os fatores que influenciam a geração, as restrições de reciclagem e a eficiência da gestão dos RCC, é mister afirmar que há significativos desafios a serem enfrentados para que ocorra a reversão do quadro de degradação ora vigente (MENEGAKI e DAMIGOS, 2018; JUNIOR et al., 2019; HACKENHAAR et al., 2019).

O Brasil evidencia geração per capita de RCC inferior à de países mais desenvolvidos. No entanto, o valor contabilizado pode não corresponder à geração real desses resíduos, pois se refere apenas à parcela dos resíduos sobre os quais os municípios possuem informações (IPEA, 2012). A ausência de dados de geração e de tratamento ambientalmente adequado é desafio reconheci- do e pautado como meta para a gestão nacional (BRASIL, 2012; BRASIL, 2016). Mas esse não é um desafio exclusivo do país; na União Europeia (UE), até mesmo a classificação dos RCC trouxe transtornos aos valores reportados pelos países até o ano de 2011, já que apenas alguns deles incluíam os resíduos de terraplenagem. Na UE, a meta de reúso e reciclagem de $70 \%$ dos RCC até o ano de 2020 já havia sido ultrapassada por alguns de seus países há mais de uma década. No entanto, permanece como desafio para outros, que nem mesmo possuem valores conhecidos de geração (EUROPEAN COMISSION, 2011). Segundo Wang et. al. (2016), na China o crescimento da geração de RCC evidenciado no período de 2001 a 2013 foi obtido por meio de estimativa da geração realizada a partir de dados públicos de construção e demolição. Ainda segundo o autor, das mais de 3 bilhões de toneladas de RCC produzidas anualmente, apenas $10 \%$ são recicladas.

A ausência de dados, no Brasil, conflita com a obrigatoriedade legal de serem estabelecidas, pelos municípios, as diretrizes locais para o manejo adequado desses resíduos. De acordo com WU et al. (2014), existem várias metodologias de quantificação de RCC, tais como: a) medidas diretas em campo; b) medições indiretas; c) cálculo da taxa de geração para uma atividade específica; d) utilização da geração per capita como fator de multiplicação; e) extrapolação dos valores financeiros; f) cálculo com base em área construída; g) balanço de massa e vida útil de um produto; h) método de acumulação de um sistema de classificação; i) método do modelo de variáveis. Como evidenciado por Paz e Lafayette (2016), grande parte dessas metodologias foi desenvolvida com o intuito de auxiliar a gestão dos RCC em obras e municípios.

Correlações entre a geração de RCC e as características e etapas de obras foram estudadas por pesquisadores brasileiros e, a partir disso, foram propostas ferramentas para estimati- 
va de resíduos (MÁLIA, BRITO e BRAVO, 2011; PAZ, LAFAYETTE e SOBRAL, 2018). No entanto, considerando que tais estimativas ocorrem em obras regulares e planejadas, os valores obtidos podem não representar grande parte das obras de construção realizadas no país. Além disso, não contemplam os RCC gerados nas atividades de demolição.

No Brasil, muitos municípios utilizam a proposição de Pinto (1999) para estimar a geração de RCC em seus territórios. Essa metodologia considera os seguintes indicadores: áreas de construção aprovadas (geração de $150 \mathrm{~kg}$ RCC/m2 de área construída); carga transportada pelos catadores; e monitoramento do destino final. No entanto, segundo Córdoba et al. (2019), dentre esses indicadores o mais efetivo é o uso dos dados de destinação final, que na maioria dos municípios brasileiros inexistem. Também é usual no país a adoção dos dados publicados nos panoramas da Associação Brasileira de Empresas de Limpeza Pública e Resíduos Especiais (ABRELPE), nos diagnósticos anuais disponibilizados pelo Sistema Nacional de Informações sobre Saneamento (SNIS) e em pesquisas realizadas em territórios específicos, como o realizado na versão preliminar do Plano Nacional de Resíduos Sólidos (BRASIL, 2012). Considerada a fragilidade dos dados, o uso de ajustes matemáticos pode auxiliar nessas estimativas com o uso de variáveis socioeconômicas específicas dos territórios.

As correlações lineares, conhecidas com correlações de Pearson, são amplamente empregadas para verificar a existência de relação entre duas variáveis independentes. De acordo com a lógica proposta por Pearson, duas variáveis não dependentes entre si podem possuir uma correlação linear de ocorrência, desde que seus valores não gerem desvios do valor médio muito diferentes entre si. Assim, se a correlação for perfeita, então o desvio de uma variável em relação ao valor médio é idêntico ao desvio da outra, também em relação ao seu valor médio. Não necessariamente os valores são os mesmos ou suas médias são as mesmas, mas há simetria quando seus desvios são comparados aos valores gerados na ocorrência de cada variável. Numericamente, valores próximos de 1 ou -1 revelam perfeitas correlações; valores próximos de 0 , muito baixa; acima de 0,3, geralmente, são aceitáveis correlações lineares. Na prática, a avaliação da significância de uma correlação linear é feita por meio de um teste de hipótese da existência de um coeficiente linear (COHEN, 1988; FERNANDES, 1999; Pearson apud FIGUEIREDO FILHO; SILVA JÚNIOR, 2009). Neste trabalho, são consideradas variáveis independentes: a geração de RCC e os fatores socioeconômicos.

Curvas ajustadas a um conjunto de valores geralmente produzem erros residuais, que podem ser entendidos como a diferença entre o valor estimado e o valor observado. Em estatística, o conceito de resíduo pode ser utilizado para comparar diferentes modelos entre si, em relação aos valores observados, por meio de um coeficiente, R2, conhecido como coeficiente de determinação. Quanto maior o valor de R2, maior a quantidade de valores observados que podem ser explicados por meio de uma relação estabelecida em um modelo matemático, ajustado aos valores observados. Nesse contexto, entende-se como modelo matemático a expressão algébrica capaz de traduzir um fenômeno observado no mundo físico (SUBRAMANIAN, A.; COUTINHO, A. S.; SILVA, 2007; COHEN, 1988; FERNANDES, 1999). No caso do presente trabalho, o fenômeno avaliado é a geração municipal de RCC.

De acordo com Rosado et al. (2019), a geração de RCC estimada no Brasil é da ordem de 100 miIhões de toneladas/ano, e $20 \%$ desse total é gerado pelo estado de São Paulo. Em 2012, menos de $20 \%$ dos municípios paulistas possuíam áreas previstas para a reciclagem dos RCC e menos de $60 \%$ realizavam algum tipo de beneficiamento 
ou de reutilização desses resíduos (SÃO PAULO \& SINDUSCON, 2012; SÃO PAULO, 2014). A inexistência de unidades de destinação adequadas para o tratamento de RCC evidencia que grande parcela desses resíduos vem sendo aterrada ou contribui para a poluição difusa do território. $\mathrm{O}$ descontrole da geração e do destino dos RCC enseja a ocorrência de perdas econômicas de materiais que poderiam ser reintroduzidos na cadeia produtiva e a impactos ambientais imensuráveis.

De acordo com Marques Neto (2009), há alguns municípios paulistas (Campinas, Diadema, Guarulhos, Jundiaí, Piracicaba, Ribeirão Preto, Santo André, São Carlos, São José do Rio Preto, São José dos Campos e Tremembé) cuja situação legal se destaca historicamente da situação dos demais, em função dos esforços para elaboração de Planos de Gestão de Resíduos da Construção Civil, anteriormente à promulgação da Lei 12305/2010, em convergência com o disposto pela resolução CONAMA 307/2002. Mesmo considerando que nesses territórios esforços ainda precisam ser invitados para o alcance da efetividade de gestão, os dados e informações por eles disponibilizados podem ser considerados norteadores de ações para outros municípios do estado.

Em função do cenário vigente no estado de São Paulo, foram estabelecidas as seguintes metas de gestão dos RCC, para pleno atendimento até 2019, a saber: eliminação de disposição irregular; implementação de módulo específico no Sistema de Gerenciamento online já existente; implantação de áreas de recebimento, transbordo e triagem; reutilização e reciclagem de $70 \%$ dos materiais; exigência dos planos de gerenciamento de grandes geradores; além de ações voltadas à redução de geração (SÃO PAULO, 2014). Visando a corroborar a busca pela eficiência da gestão e gerenciamento dos RCC e entendendo que o primeiro passo consiste em aumentar a qualidade dos dados sobre a ocorrência desses resíduos nos municípios, este trabalho foi concebido, com o objetivo de produzir modelos matemáticos de aproximação estatística para estimativa de geração de RCC em municípios do estado de São Paulo, com o uso da hipótese de que os dados de geração dessa classe de resíduos nos onze municípios do Estado com maior qualidade de gestão são confiáveis.

\section{METODOLOGIA}

$O$ presente trabalho se enquadra na metodologia que utiliza o fator de multiplicação da geração per capita para estimar a geração municipal de RCC e foi desenvolvido como uma pesquisa aplicada quantitativa (GERHARDT; SILVEIRA, 2009). Tendo como base essencial de estimativa da geração de RCC função já adotada por municípios da Região Metropolitana do Vale do Paraíba e Litoral Norte (RMVPLN), foram utilizados dados socioeconômicos disponíveis em sítios confiáveis e amplamente adotados em gestão e gerenciamento de resíduos no Brasil (CARAGUATATUBA, 2014). As principais etapas metodológicas são apresentadas na Fig. 1. 


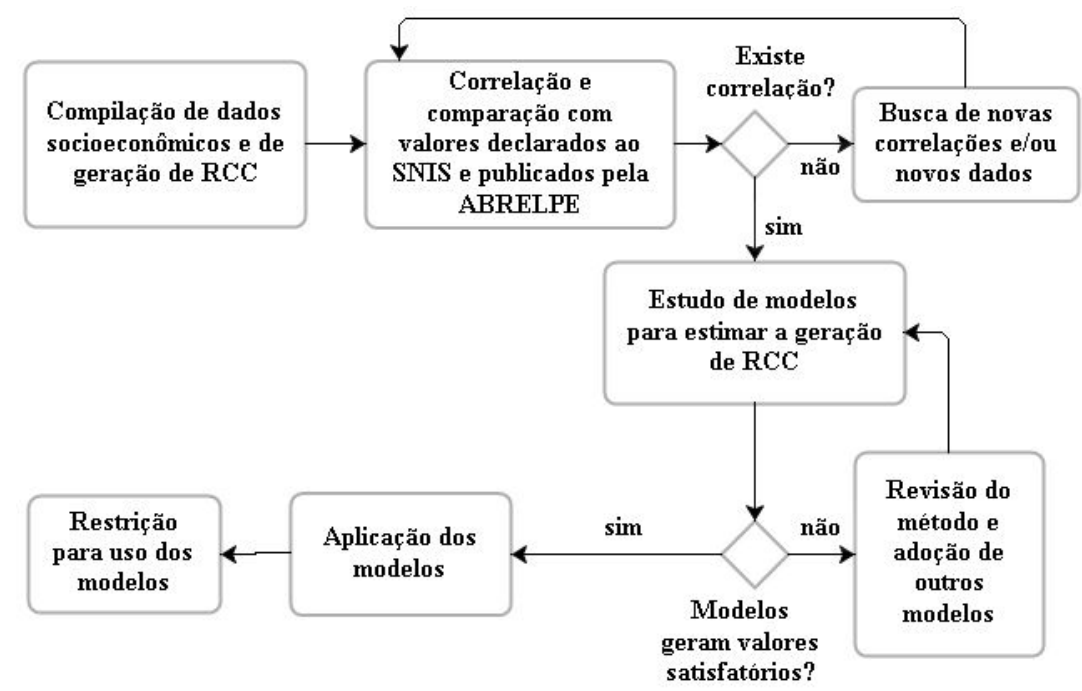

Figura 1 - Esquema da metodologia adotada no presente trabalho.

Na Fig. 1, os dados e procedimentos adotados abrangem:

a. Compilação de dados socioeconômicos relacionados à geração de RCC, tais como população, renda, renda per capita, investimentos no setor de construção civil, salários pagos no setor, para todas as macrorregiões brasileiras, entre os anos de 2007 a 2014, disponíveis gratuitamente em sítios do Instituto Brasileiro de Geografia e Estatística (IBGE, 2016b);

b. Compilação de dados socioeconômicos relacionados à geração de RCC, tais como população, renda, renda per capita, capacidade de compra, para o Estado de São Paulo, entre os anos de 2007 a 2014 disponíveis gratuitamente em sítios do Instituto Brasileiro de Geografia e Estatística (IBGE, 2016a);

c. Compilação de dados de geração de RCC, declarados por todos os municípios do estado de São Paulo, ao SNIS, no período de 2010 a 2014;

d. Compilação e comparação dos dados de geração de RCC em macrorregiões brasileiras, publicados pela ABRELPE e declarados ao SNIS, entre 2007 e 2014; e. Aplicação de métodos de correlação linear de Pearson e teste de hipótese com nível de significância de 5\%;

f. Seleção de dados de melhor qualidade no estado de São Paulo, acerca da geração de RCC declarada ao SNIS, com base em exemplos citados pelo Plano de Resíduos Sólidos do Estado de São Paulo (São Paulo, 2014), para gerar valores estatísticos aplicáveis ao estado de São Paulo;

- Critérios de qualidade de dados:

- Possuir plano de gestão de RCC de acordo com a Resolução Conama 307 há mais de 5 anos;

- Não declarar geração nula de RCC ao SNIS;

g. Proposição de modelo matemático para a estimativa de geração municipal de RCC;

h. Validação do modelo proposto, por meio da estimativa de geração municipal de RCC, nos municípios com dados de melhor qualidade no estado de São Paulo. Para obtenção dos dados de melhor qualidade, foram tomados como base os 11 municípios, citados pelo Plano Estadual de Resíduos Sólidos, que possuem Planos de Gestão de Resíduos da Construção Civil desde a primei- 
ra década de 2000, a saber: Campinas, Diadema, Guarulhos, Jundiaí, Piracicaba, Ribeirão Preto, Santo André, São Carlos, São José do Rio Preto, São José dos Campos e Tremembé, além de trabalhos citados pelo mesmo plano (SÃO PAULO, 2014). Com isso, foi possível agrupar todos os dados declarados por 11 municípios, entre 2010 e 2013, em um conjunto de 42 valores de população, renda per capita e geração per capita de resíduos ao ano (foram 11 valores em 4 anos, totalizando, a priori 44, mas subtraindo dois valores nulos, com 42 valores, a posteriori).

i. Determinação das condições de aplicação do modelo.

\section{RESULTADOS}

\subsection{Geração macrorregional e estadual de RCC}

Para as macrorregiões brasileiras, foi possível identificar correlações estatísticas entre a ge- ração anual de RCC e os dados socioeconômicos (ABRELPE, 2016; IBGE, 2016b). Dentre os fatores avaliados, verificou-se que a geração de RCC nas macrorregiões relaciona-se com as seguintes características:

- número de habitantes;

- potencial econômico e individual para promover alterações no meio (seja construindo novas estruturas ou reformando as já existentes);

- quantias em dinheiro investidas no setor de construção civil; e

- quantias pagas aos trabalhadores do setor.

A Fig. 2 apresenta a relação entre renda per capita e a geração de RCC nas 5 macrorregiões brasileiras (Norte, Nordeste, Centro-Oeste, Sudeste e Sul), no período entre 2007 e 2012. Para a macrorregião sudeste, foi traçada uma curva de regressão linear.

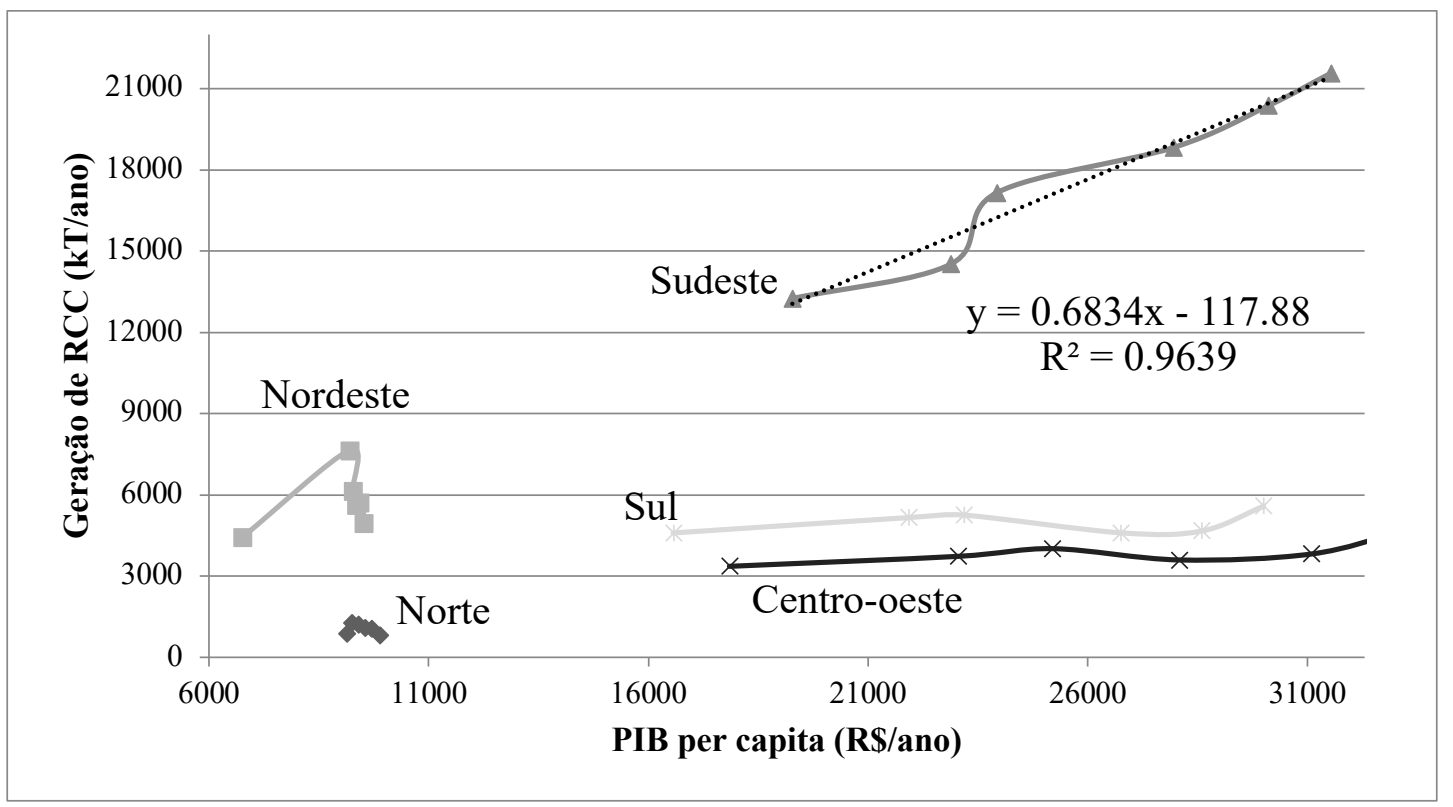

Figura 2 - Relação histórica entre a massa de RCC e a renda per capita anual nas 5 macrorregiões brasileiras.

Semelhantemente, foi verificado se existe relação entre a geração de RCC e o pagamento de salários ou remunerações a trabalhadores do se- tor da construção civil, nas 5 macrorregiões brasileiras, conforme mostrado na Fig. 3. 


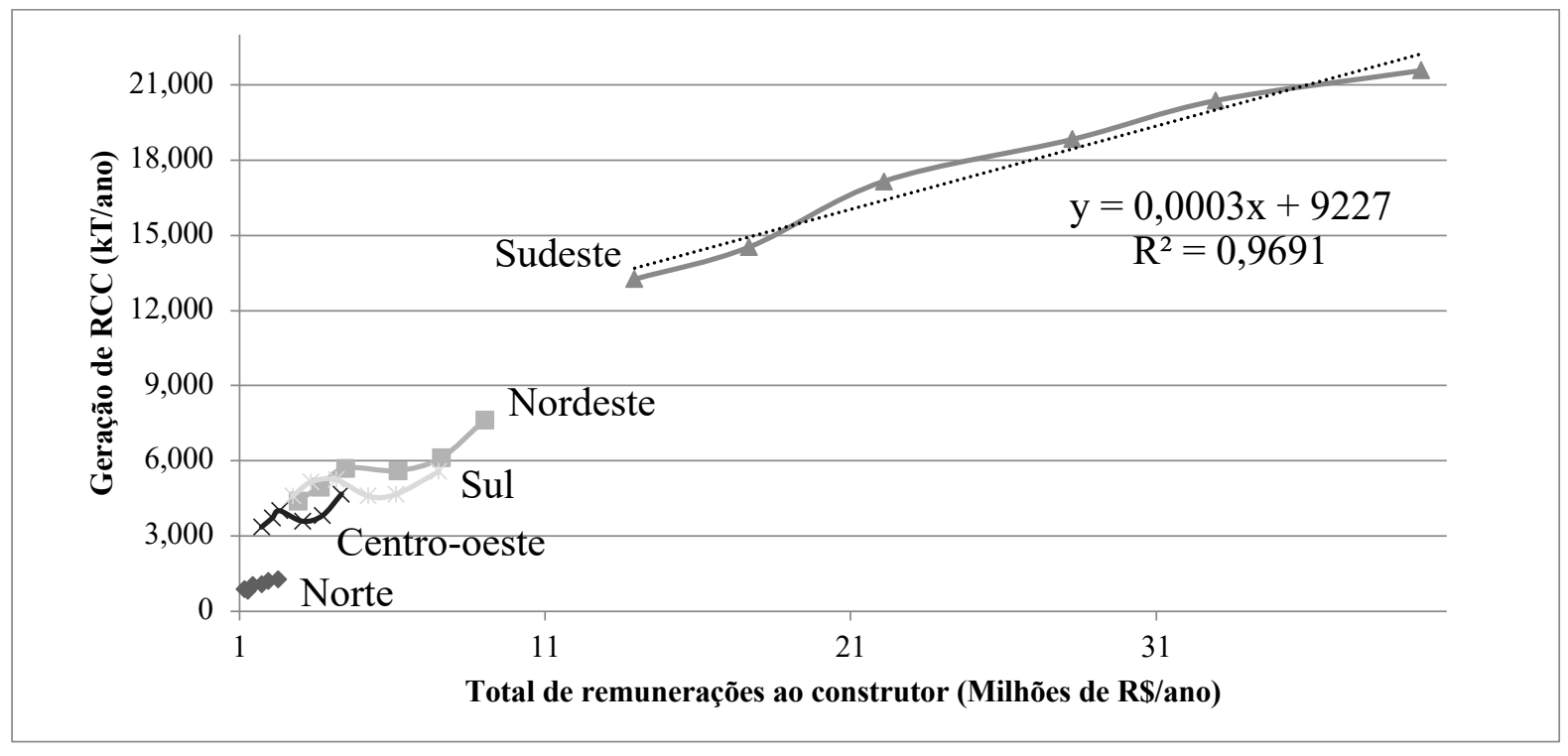

Figura 3 - Relação histórica entre a massa de RCC e a remuneração no setor de construção civil nas 5 macrorregiões brasileiras.

A relação entre a evolução populacional e de geração de RCC, em todas as macrorregiões brasileiras, é apresentada na Fig. 4.

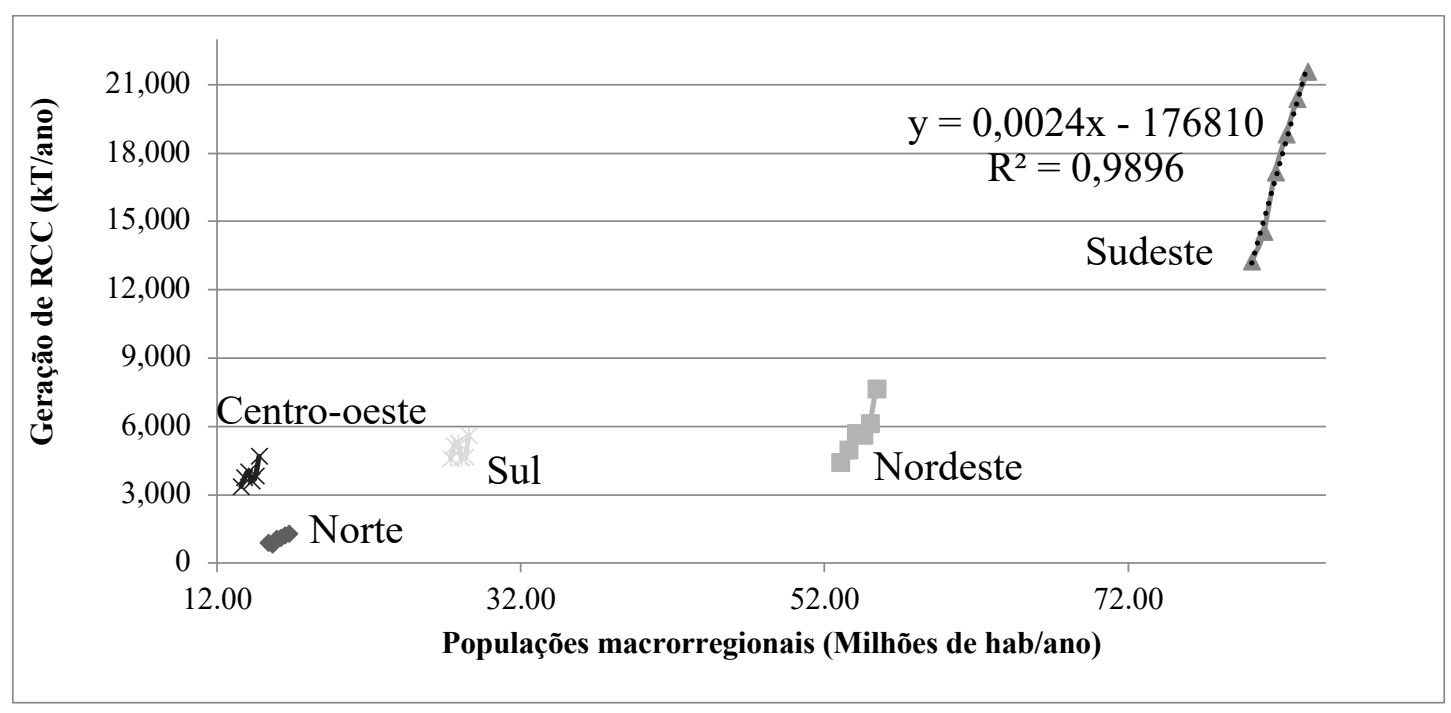

Figura 4 - Relação histórica entre a massa de RCC e a população anual nas 5 macrorregiões brasileiras.

Na Fig. 5, é apresentada a relação entre investimentos no setor de construção civil e a geração de RCC, com valor de R2 da regressão linear próxima de 0,99, para a região Sudeste. 


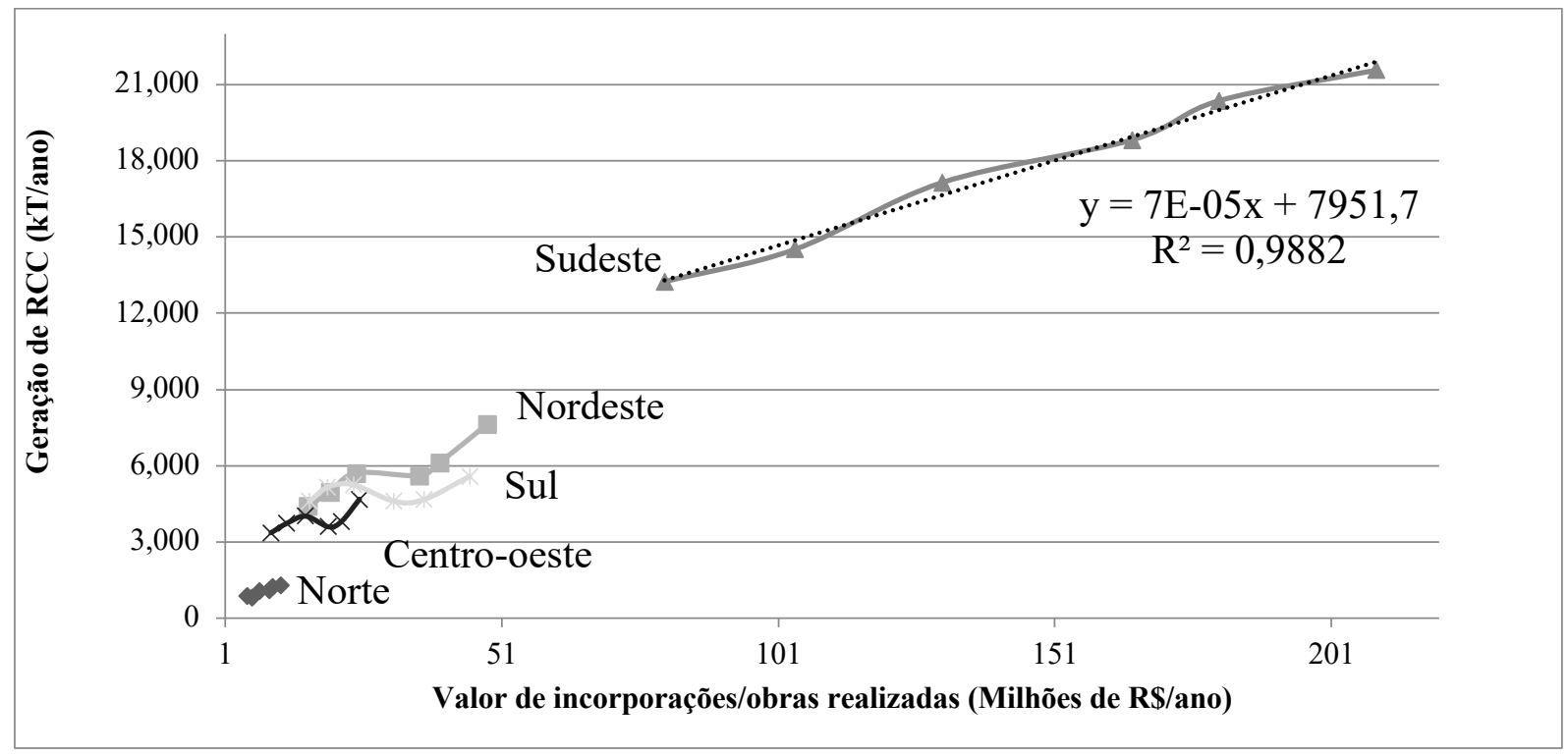

Figura 5 - Relação entre a evolução da massa de RCC e o valor de incorporações e obras realizadas nas 5 macrorregiões brasileiras.

Nota-se que, em todas as relações, a região Sudeste apresenta os maiores valores de geração de RCC, possuindo curvas de maior comprimento gráfico e com valores de R2 superiores a 0,96. A macrorregião norte, por outro lado, possui os menores valores de geração de RCC, com curvas visivelmente mais curtas, no período avaliado. Em relação à renda per capita (Fig. 2), praticamente não houve variação na geração de RCC, nas ma- crorregiões Sul e Centro-Oeste. Contudo, de um modo geral, observando as Fig. 2, 3, 4 e 5, é possível notar padrões crescentes e (principalmente no Sudeste) lineares de evolução da geração de RCC com o aumento da renda per capita, das remunerações pagas, dos investimentos realizados no setor de construção e do número de habitantes.

Correlações de Pearson foram calculadas para as relações apresentadas nas Fig. 2, 3, 4 e 5 (Tabela 1).

Tabela 1 - Correlações lineares de Pearson em macrorregiões brasileiras.

\begin{tabular}{|c|c|c|c|c|}
\hline Macrorregião & $\begin{array}{c}\text { Relação de } \\
\text { Pearson: } \\
\text { remunerações X } \\
\text { Geração } \\
\text { de RCC (kt/ano) }\end{array}$ & $\begin{array}{c}\text { Relação de } \\
\text { Pearson: } \\
\text { população total X } \\
\text { Geração } \\
\text { de RCC (kt/ano) }\end{array}$ & $\begin{array}{c}\text { Relação de } \\
\text { Pearson: } \\
\text { Renda per capita X } \\
\text { Geração } \\
\text { de RCC (kt/ano) }\end{array}$ & $\begin{array}{c}\text { Relação de } \\
\text { Pearson: } \\
\text { Investimentos } \\
\text { em obras X } \\
\text { Geração } \\
\text { de RCC (kt/ano) }\end{array}$ \\
\hline Sudeste & 0,980 & 0,980 & 0,982 & 0,996 \\
\hline Sul & 0,330 & 0,740 & 0,330 & 0,740 \\
\hline Nordeste & 0,510 & 0,970 & 0,507 & 0,966 \\
\hline Centro-oeste & 0,740 & 0,900 & 0,742 & 0,882 \\
\hline Norte & 0,400 & 0,970 & 0,371 & 0,984 \\
\hline Média & 0,600 & 0,910 & 0,586 & 0,914 \\
\hline
\end{tabular}

Conforme mostrado na Tabela 1, existem valores elevados de correlação linear não apenas entre geração de RCC e crescimento populacional, mas também entre remunerações pagas a trabalhadores e investimentos do setor de construção, bem como a renda per capita. Observa-se que, no Sudeste, os valores são sempre muito elevados, próximos de 1 e superiores a 0,926 que, em teste de hipótese de correlação linear utilizando a distribuição t de Student, com valor crítico para 
a significância de correlação tendendo a $0 \%$ e amostra com 8 valores, representa o limite para declaração errônea de que há correlação, conforme demonstrado na Eq. 1.

Coeficiente de correlação para o menor valor possível de significância em teste $t$ de Student.

$r=\frac{t}{\sqrt{(n-2)+t^{2}}}=\frac{6}{\sqrt{6}+5,99}=0,926$

Sendo:

$r$ = correlação linear entre as variáveis;

$\mathrm{n}$ = graus de liberdade;

$\mathrm{t}=$ distribuição $\mathrm{t}$ de Student: $\mathrm{t}(\mathrm{n}-2)$.
No estado de São Paulo, os dados de geração de RCC apresentados pelos municípios ao SNIS não possuem valores regulares. Mesmo para os 11 municípios que possuem Planos de Gestão de Resíduos da Construção Civil, desde a primeira década de 2000, pouca simetria é observada entre a geração de RCC e os dados socioeconômicos do IBGE. Na Fig. 6, é mostrado o caráter aparentemente aleatório da relação entre a geração per capita de RCC e a renda per capita, entre 2010 e 2013, dos municípios de Campinas, Diadema, Guarulhos, Jundiaí, Piracicaba, Ribeirão Preto, Santo André, São Carlos, São José do Rio Preto, São José dos Campos e Tremembé.

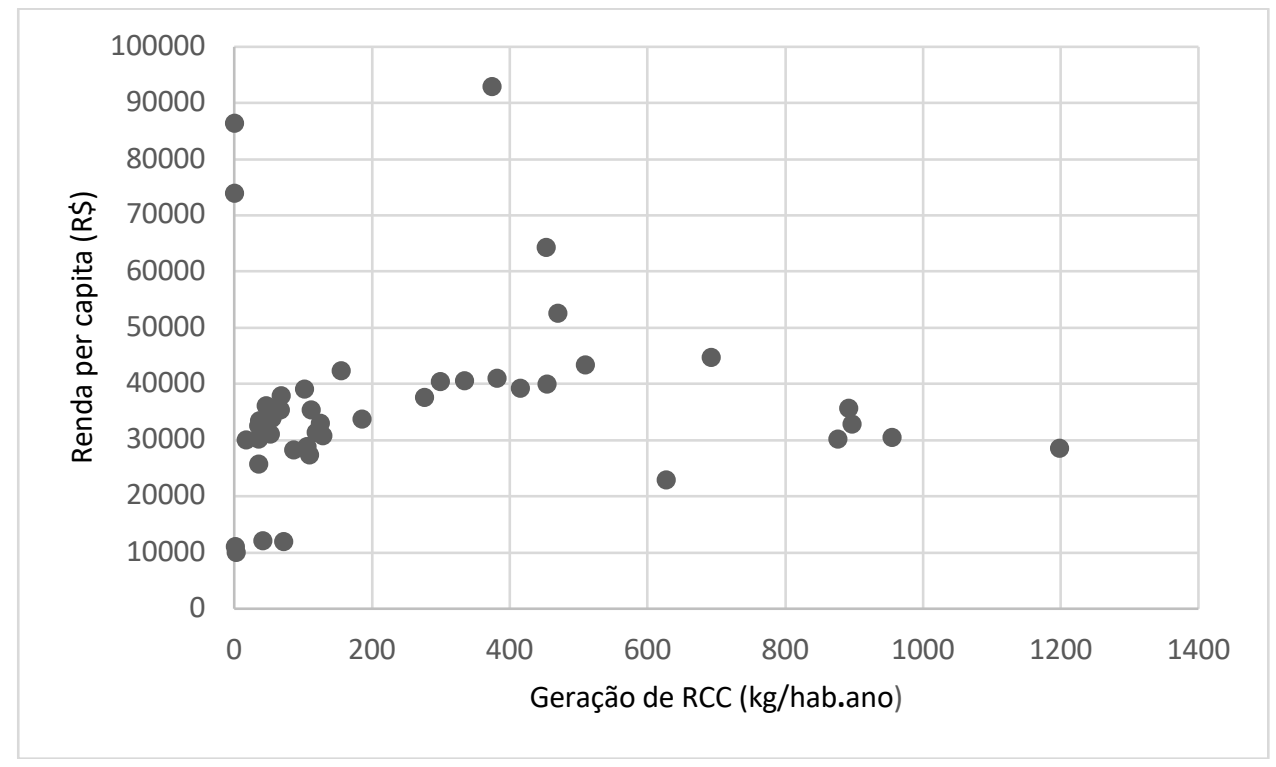

Figura 6 - Relação entre renda e geração de RCC de 2010-2013.

Na Fig. 7, comparação semelhante é feita entre a geração per capita de RCC e a população de cada um dos municípios. 


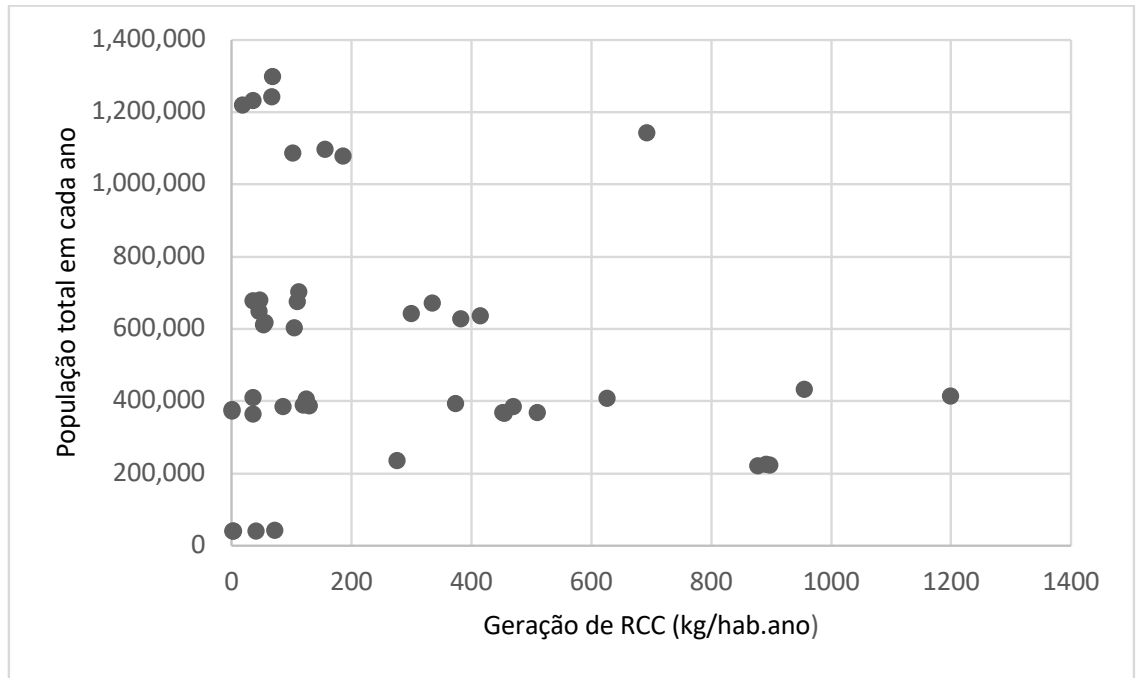

Figura 7 - Relação entre população e a geração per capita de RCC de 2010-2013.

\subsection{Geração estimada de RCC}

Tentativas de estimar a geração municipal de RCC a partir de correlações lineares em macrorregiões não foram bem-sucedidas. Todos os valores obtidos para a geração per capita anual de RCC em municípios paulistas, a partir de funções lineares de correlações da Tabela 1, ou resultaram em valores extremamente pequenos, subestimados, ou em valores exorbitantes, superestimados. Os resíduos estatísticos (entre os valores obtidos por meio de equações lineares e os valores declarados ao SNIS) podem ser verificados na Fig. 10. Considerando que esses resíduos revelam que o modelo linear (obtido a partir de correlações em escala macrorregional) está consideravelmente distante, em praticamente todos os pontos modelados linearmente, dos valores declarados (em escala municipal), foi descartado o uso de correlações lineares de valores em escalas macrorregionais, para estimar a geração de RCC em escala municipal.

O conjunto de dados declarados pelos 11 municípios do Estado de São Paulo foi, então, disposto em ordem crescente, conforme mostrado na Fig. 8.

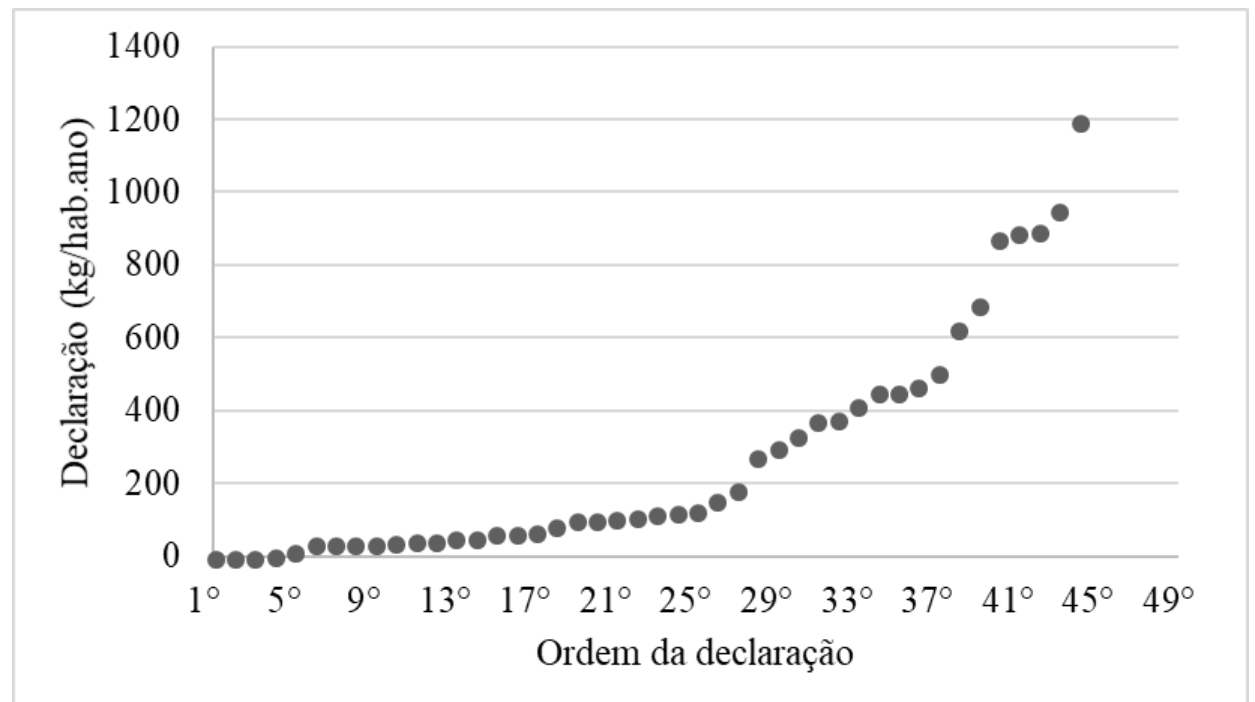

Figura 8 - Distribuição em ordem crescente das declarações de 11 municípios paulistas entre 2010 e 2013. 
O formato característico de uma função potência da curva da Fig. 8 serviu de base para a construção de gráficos que relacionam a população normalizada por valores de geração per capita de resíduos, no eixo das ordenadas, com a própria geração per capita de resíduos, no eixo das abscissas (Fig. 9 (a)), e da mesma forma, relacionam a renda per capita normalizada pela geração per capita de resíduos, no eixo das ordenadas, com a geração per capita de resíduos, no eixo das abscissas (Fig. 9 (b)).

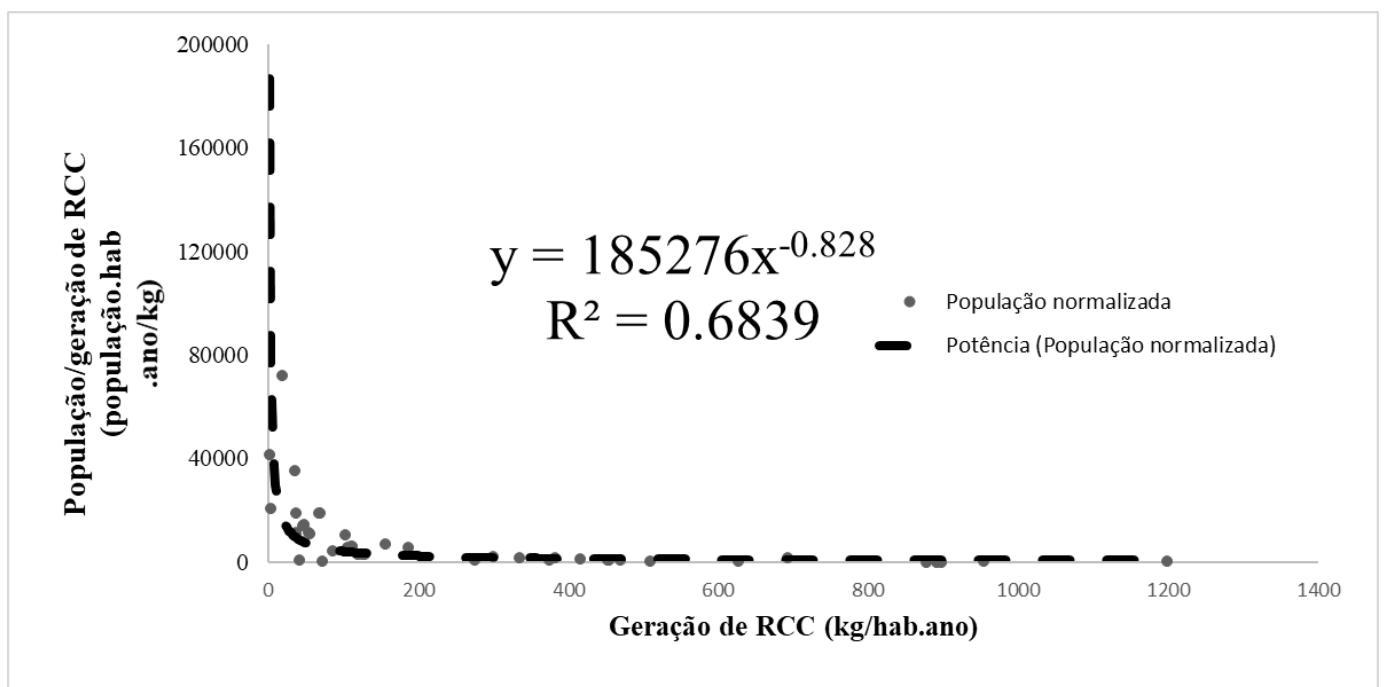

a)

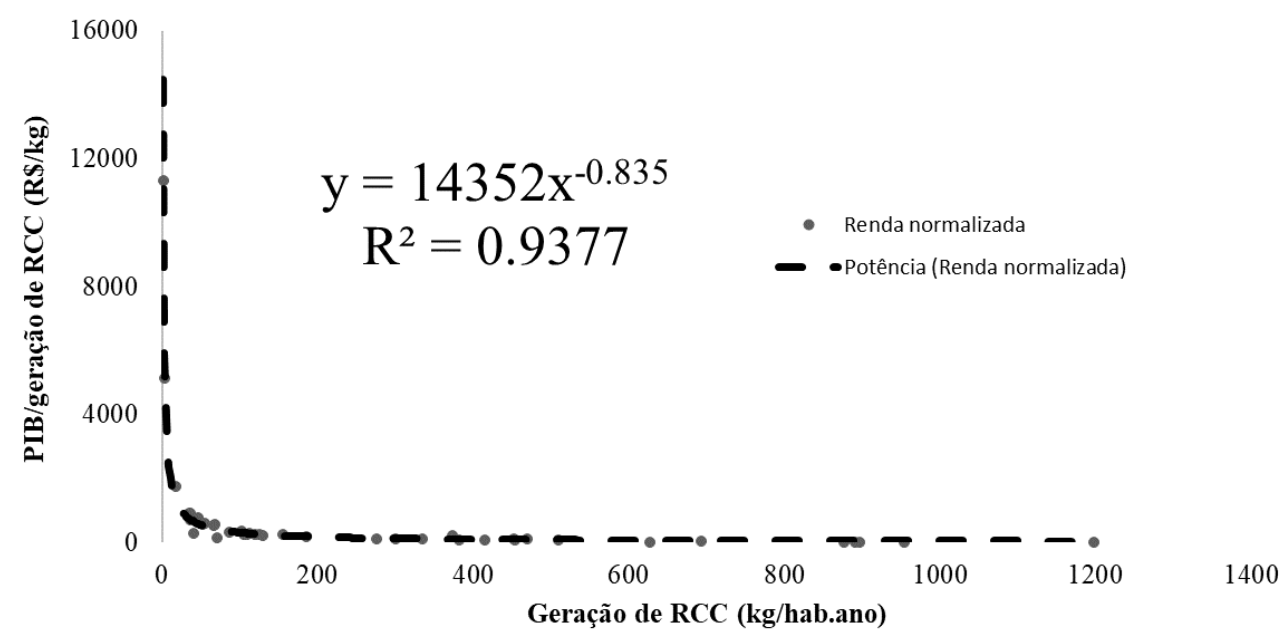

b)

Figura 9 - Relações estatísticas. a) população e geração de RCC; b) renda per capita e geração de RCC.

Com as estatísticas de cada gráfico da Fig. 9 (a) e (b), foi possível obter duas funções potência, para estimativa da geração per capita de RCC no estado de São Paulo, conforme demonstrado na Eq. 2.

Manipulação algébrica da função da Fig. 9 (a) e (b).

$\frac{V}{x}=k \cdot x^{m} \rightarrow \frac{V}{k}=x \cdot x^{m} \rightarrow \frac{V}{k}=x^{1+m} \rightarrow x=\left(\frac{V}{k}\right)^{\frac{1}{1+m}} \rightarrow x=\sqrt[c]{\frac{V}{k}}$

Sendo: $c=1+m$ 
$\mathrm{Na}$ Eq. 3, é apresentado o modelo resultante da manipulação algébrica demonstrada na Eq. 2, para estimativa da geração de RCC com base nos valores de população municipal (Vp) e uma abrangência de aproximadamente $68 \%$ dos valores observados (Fig. 9 (a)). Nessa equação, a variável $x$ é uma função da variável $V_{p}$. Assim, inserindo valores de população (número de habitantes), obtém-se o valor equivalente de geração de RCC $(\mathrm{kg} /$ hab.ano). Note-se que, quanto maior o valor da população, maior será a geração de RCC.

Modelo para estimar a geração de RCC com base em valores de população $\left(\mathrm{V}_{\mathrm{p}}\right)$.

$$
x=\sqrt[0,172]{\frac{V p}{185.276}}
$$

Sendo:

$\mathrm{x}$ = geração de RCC ( $\mathrm{kg} / \mathrm{hab} \cdot a n o)$;

$V_{p}=$ população municipal.

A Eq. 4, por sua vez, apresenta o modelo que estima a geração de RCC, com base nos valores de renda per capita, com uma porcentagem de tradução dos dados da Fig. 9 (b) de, aproximadamente, 93,8\%. Essa equação é semelhante à Eq. 3, com algumas especificidades, tais como a constante no denominador dentro da raiz e uma taxa de aumento na geração de RCC, em função do aumento da renda per capita, ligeiramente maior do que a da equação anterior (Eq. 3). Assim, inserindo valores de renda per capita $(R \$ /$ hab.ano), obtém-se o valor correspondente de geração de RCC (kg/hab.ano).
Modelo para estimar a geração de RCC com base em valores de renda per capita $\left(V_{r}\right)$.

$$
x=\sqrt[0,165]{\frac{V r}{14.352}}
$$

Sendo:

x= Geração de RCC (kg/hab.ano);

$\mathrm{V}_{\mathrm{r}}=$ Valor da Renda Per Capita (R $\$ /$ hab.ano).

Para que os modelos propostos sejam coerentes com a realidade observada no Estado, foram adotados, como limites de uso de cada função (Eq. 3 e 4), o valor mínimo não nulo (1 kg/hab. ano) e máximo (1198 kg/hab.ano), dentro do conjunto de 42 valores distribuídos em ordem crescente na Fig. 8. Assim, a Eq. 3 deverá ser usada apenas em municípios do Estado cujo número de habitantes esteja compreendido no intervalo: $185.276 \leq V_{p} \leq 627.067$. Seguindo esse mesmo raciocínio, a Eq. 4, por sua vez, deverá ser usada em municípios que tiverem renda per capita anual dentro do seguinte intervalo: $14.352 \mathrm{R} \$ / \mathrm{hab}$. ano $\leq \mathrm{V}_{\mathrm{r}} \leq 46.223 \mathrm{R} \$$ /hab.ano.

De forma comparativa entre duas estimativas de funções diferentes com os valores declarados, a Eq. 4 foi utilizada para estimar valores de geração de RCC de todos os 11 municípios paulistas usados como referência no presente trabalho, junto com os valores declarados ao SNIS pelos mesmos municípios e estimativas feitas a partir do modelo linear. A comparação está apresentada na Fig. 10. 


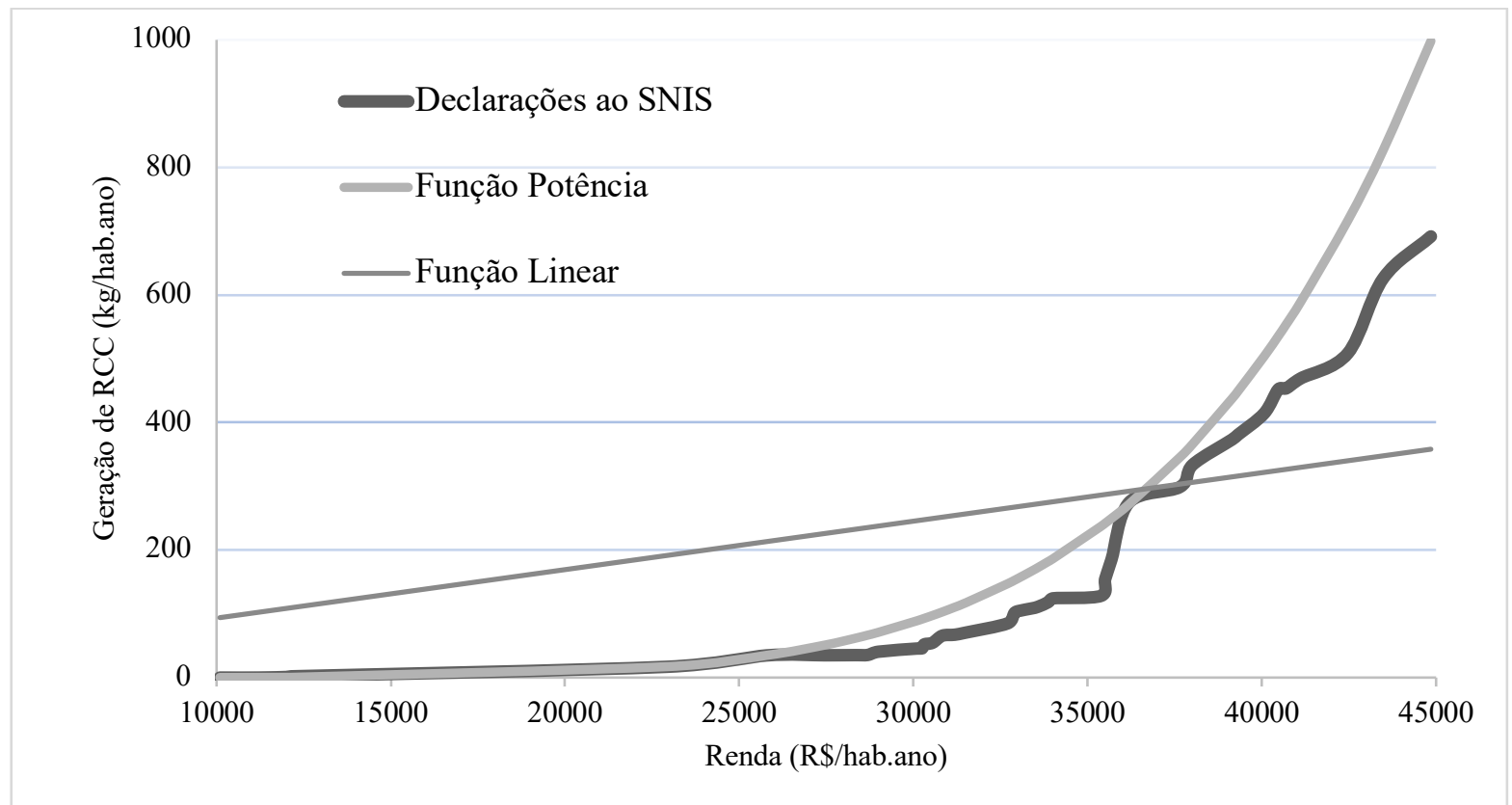

Figura 10 - Comparação, com a declaração ao SNIS, da geração de RCC do modelo de função da renda per capita, a partir da função potência e da função linear.

\section{DISCUSSÃO}

Muitas são as possíveis justificativas para as relações entre geração de resíduos e os aspectos socioeconômicos. Considerando que uma grande quantidade de autores relaciona o aumento da quantidade de áreas construídas com a maior geração de RCC (KOFOWOROLA; GHEEWALA, 2009; PINTO, 1999; DING; XIAO, 2014; LAGE et al., 2010; KERN et al., 2015, entre outros), é possível associar o aumento no número de indivíduos que fazem uso de edificações com um aumento na demanda por novas construções ou reformas em obras já executadas. Assim, esperase que o incremento populacional em qualquer local resulte na materialização da demanda por novas construções e no consequente aumento da geração de RCC, em quantidades que variam em função do tipo de construção e dos métodos adotados. Contudo, como pode ser observado na Fig. 4, incrementos populacionais macrorregionais ocorrem em velocidades inferiores ao incremento na geração de RCC, de modo que as curvas de relação entre essas duas variáveis (po- pulação e geração de RCC) possuam inclinações superiores àquelas observadas em função de outras variáveis, tais como renda, remunerações ou valores investidos no setor de construção civil (Fig. 2, 3 e 5).

A Tabela 1 evidencia uma maior correlação em escala macrorregional entre a geração de RCC, os investimentos no setor e o crescimento populacional. No entanto, não é possível dizer que, na realidade em escala regional e municipal, a maior geração de resíduos está relacionada com esses aspectos socioeconômicos.

Semelhantemente aos resultados apresentados no presente trabalho, estudos comparativos entre a geração de RCC em diversos países da Europa, realizados pela Agência Europeia do Ambiente (EEA, 2009), apontam que as variáveis de maior importância para determinar a geração de RCC não são os aspectos relacionados ao número de habitantes dos países da União Europeia, mas sim fatores relativos à tradição de cada país ou região para a construção com menores gerações 
de resíduos, em relação às peculiaridades geológicas e geográficas, bem como à robustez da atividade econômica do setor da construção.

O uso de dados macrorregionais deve ser acompanhado de elevada cautela, pois valores estatísticos médios, como a renda per capita, nem sempre refletem a capacidade local de realização de atividades de construção. Conforme pode ser visto na Fig. 2, enquanto as regiões Norte, Sul e Centro-Oeste apresentam mínimas variações na geração de RCC, com o passar do tempo e com o aumento nos valores de renda per capita, o Nordeste apresentou uma queda na geração de RCC e uma aparente estagnação nos valores de renda, em oposição ao Sudeste, em que tanto renda per capita como geração de RCC foram progressivamente maiores, no período entre 2007 e 2012. Assim, entende-se que cada macrorregião brasileira se comporta de modo peculiar, por razões diversas. Por exemplo, em uma macrorregião onde o agronegócio esteja entre as principais atividades econômicas, em períodos de crescimento econômico, um maior volume de renda poderá ser alcançado com pouca geração de RCC e um maior volume de outras classes de resíduos.

No processo de elaboração de um modelo matemático para estimar a geração de RCC no estado de São Paulo, a construção do gráfico da Fig. 8 possibilitou verificar o aumento exponencial com que as declarações foram feitas ao longo do período; com isso, foram construídas as curvas das Fig. 9 (a) e 9 (b) e, em seguida, as Eq. 3 e 4. Observa-se na Fig. 9 (b) que a relação entre renda e geração de resíduos possui melhor curva e menor variação residual entre a função e os dados declarados; assim, as estatísticas obtidas por meio dessa curva são mais indicadas para estimar a geração de RCC municipal, conforme modelo apresentado na Fig. 10.

Os valores do coeficiente de determinação (R2) apresentados nas Fig. 9 ((a) e (b)) podem ser in- terpretados da seguinte maneira: o modelo sugerido, com as estatísticas da Fig. 9 (a), representa $68,4 \%$ dos valores declarados ao SNIS pelos 11 municípios selecionados, em todos os anos avaliados; o modelo sugerido com as estatísticas da Fig. 9 (b), por sua vez, representa 93,8\% dos valores das declarações ao SNIS dos mesmos municípios, em todos os anos avaliados. Além disso, no modelo da Fig. 9 (b), observa-se um melhor ajuste dos dados declarados em relação à função potência. Logo, entende-se que o modelo construído como uma função da renda per capita municipal é mais indicado para estimar a geração de RCC de municípios paulistas.

O tipo de função encontrada como modelo para estimar a geração paulista de RCC assemelha-se a um dos modelos adotados por pesquisadores da Universidade de Lisboa (BERNARDO; CASTILHO; BRITO, 2016). De acordo com os autores, a geração de $\mathrm{RCC}$ em $\mathrm{t} / \mathrm{km}^{2}$ pode variar em função da densidade populacional seguindo uma função potência, tal que a variável densidade populacional seja elevada a uma potência inferior a uma unidade, mas multiplicada por uma constante várias ordens de grandeza maior do que a constante do presente trabalho, em função das unidades $\left(\mathrm{t} / \mathrm{km}^{2}\right.$ versus hab $\left./ \mathrm{km}^{2}\right)$ adotadas. Esses autores encontraram uma maior correlação entre geração de RCC e a idade das edificações, com coeficiente de determinação de 98,6\%, e uma menor correlação entre a geração de RCC e a densidade de áreas construídas, com um coeficiente de determinação de aproximadamente $68 \%$, que são correlações diferentes das que foram empregadas no presente trabalho.

Em função dos resultados apresentados, cabe ao município escolher se irá adotar a Eq. 2 ou 3, sabendo da variação residual associada a cada modelo e dos intervalos tidos como limitantes de uso, para a variável " $V_{p}$ " e " $V_{r}$ ". Entende-se que, caso um município em São Paulo decida utilizar os modelos propostos no presente tra- 
balho, estará adotando uma função com estatísticas, cujas informações são próprias de sistemas de ambientes considerados referência no estado de São Paulo e, também, no Brasil, para quantificação de RCC gerados; porém, com um erro residual inerente ao modelo e ao método de regressão não linear (FERNANDES, 1999), que irá distanciá-lo em maior ou menor grau da realidade municipal.

Ressalta-se que, mesmo que um município paulista não tenha recursos para realizar a caracterização inicial dos RCC gerados em seu território, para subsidiar a elaboração de um plano de resíduos, de acordo com as recomendações legais do Brasil, poderá usar dados estipulados pelo IBGE de população e renda, para estimar a geração de RCC per capita sob sua responsabilidade, como forma de obtenção de informações preliminares até que o controle sobre o manejo seja exercido pela gestão.

\section{CONCLUSÕES}

O presente trabalho apresentou um panorama geral da geração de RCC no Brasil, com enfoque no estado de São Paulo. Utilizando os dados disponíveis, foi possível verificar que variáveis macrorregionais não podem ser utilizadas para estimar a geração regional e municipal de RCC, por meio de funções lineares. Contudo, funções potência, com as estatísticas geradas a partir de valores amostrais de municípios que possuem planos de gestão de RCC elaborados há mais de 5 anos, mostraram-se mais apropriadas para determinar a geração municipal desses resíduos.

Com os resultados alcançados no presente trabalho, obtém-se uma ferramenta de modelagem matemática para estimar a geração de RCC em municípios paulistas, respeitando-se os limites propostos para sua utilização. No entanto, ressalta-se que os modelos das Eq. 2 e 3 são aplicáveis em outros territórios que possuem características do setor da construção civil semelhantes àquelas observadas nos municípios paulistas que embasaram este trabalho. Assim, não é recomendável o uso desses modelos em regiões onde parte considerável dos investimentos no setor independe da renda per capita ou do número de habitantes, como por exemplo, em regiões onde grande parte da renda advém de atividades rurais.

A metodologia de construção dos modelos para estimar a geração de RCC no estado de São Paulo pode ser adotada em outras regiões brasileiras desde que existam nesses territórios dados suficientes e confiáveis, para a obtenção de modelos regionais próprios a cada contexto cultural e socioeconômico.

\section{AGRADECIMENTOS}

Agradecemos à Fapesp pelo apoio concedido à pesquisa. Processo Fapesp n. ${ }^{\circ}$ 2016/12289-3.

\section{CONTRIBUIÇÃO DOS AUTORES}

Todos os autores contribuíram de forma igualitária.

\section{REFERÊNCIAS}

ABNT. ASSOCIAÇÃO BRASILEIRA DE NORMAS TÉCNICAS. NBR 15115/2004: Agregados reciclados de resíduos sólidos da construção civil - Execução de camadas de pavimentação: procedimentos. Rio de Janeiro, 2004a.

NBR 15116/2004: Agregados reciclados de resíduos sólidos da construção civil - Utilização em pavimentação e preparo de concreto sem função estrutural: requisitos. Rio de Janeiro, 2004b.

ABRELPE. Associação Brasileira de Empresas de Limpeza Pública e Resíduos Especiais. Panorama dos Resíduos Sólidos no Brasil. São Paulo, 2016. Disponível em:<http://www.abrelpe.org.br/panorama_apresentacao.cfm>. Acesso em: 25/09/ 2017. 
BERNARDO, M.; CASTILHO, M.; BRITO, J. DE. Demolition waste generation for development of a regional management chain model. Waste Management, v. 49, p. 156-169, 2016. https://doi. org/10.1016/j.wasman.2015.12.027

BRASIL. MCIDADES. Secretaria Nacional de Saneamento Ambiental (SNSA). Sistema Nacional de Informações sobre Saneamento: Diagnóstico do manejo de resíduos sólidos urbanos - 2014, Brasília, 2016. Disponível em: <http://www.snis.gov.br/diagnostico-residuos-solidos/diagnostico-rs-2014>. Acesso em: 07 mai 2016.

Plano Nacional de Resíduos Sólidos - versão preliminar Brasília, 2012. Disponível em: < https://sinir.gov.br/images/sinir/ Arquivos_diversos_do_portal/PNRS_Revisao_Decreto_280812. pdf>. Acesso em: 10 jun. 2019.

. Lei Federal no 12.305, de 2 de agosto de 2010. Institui a Política Nacional de Resíduos Sólidos; altera a Lei no 9. 605, de 12 de fevereiro de 1998; e dá outras providências. Diário Oficial da União, Brasília, DF, 3 ago. 2010.

CARAGUATATUBA. Aprova e institui o Plano Municipal de Saneamento Básico do Município de Caraguatatuba. Decreto $\mathbf{n}^{\circ} \mathbf{3 4}$, de 24 de fevereiro de 2014. Disponível em:http://www.legislacaocompilada.com.br/caraguatatuba/Arquivo/Documents/legislacao/html/D342014..htm. Acesso em: 10 abr. 2017

COHEN, J. Statistical Power Analysis for the Behavioral Sciences. 2nd. ed. New York: Lawrence Earlbaum Associates, 1988. https:// doi.org/10.4324/9780203771587

CONAMA. Resolução no307, de 5 de julho de 2002. Estabelece diretrizes, critérios e procedimentos para a gestão dos resíduos da construção civil. Brasília, DF: Diário Oficial da União, n. 136, p. 95-96, 17 jul. 2002.

CORDOBA, R. E.; NETO, J. C. M; SANTIAGO, C. D.; PUGLIESI, E.; SCHALCH, V.. Alternative construction and demolition (C\&D) waste characterization method proposal. Eng. Sanit. Ambient., Rio de Janeiro, v. 24, n. 1, p. 199-212, 2019. https://doi.org/10.1590/ s1413-41522019179720

DING, T.; XIAO, J. Estimation of building-related construction and demolition waste in Shanghai. Waste Management, v. 34 n. 11, p. 2327-2334, 2014. https://doi.org/10.1016/j.wasman.2014.07.029

EEA. European Environment Agency. EU as a Recycling Society: Copenhaguen, 2009. Disponível em: http://avfallnorge.web123. no/article_docs/EUgjenvinningsstudie.pdf. Acesso em: 01 mai 2017.

EUROPEAN COMISSION, (DG ENV). Service contract on management of construction and demolition waste - SR1. Final Report Task 2, 2011. Disponível em: https://ec.europa.eu/environment/ waste/pdf/2011_CDW_Report.pdf. Acesso em: 26 nov 2019.

FERNANDES, E. M. DA G. P. Estatística aplicada. Braga: Serviços de Reprografia e Publicações da Universidade do Minho, 1999.
FIGUEIREDO FILHO, D.B.; SILVA JÚNIOR, J.A. Desvendando os mistérios do coeficiente de correlação de Pearson (r). Revista Política Hoje, v. 18, n. 1, p. 115-46, 2009. https://periodicos.ufpe.br/revistas/politicahoje/article/view/3852/3156

GERHARDT, T. E. (org.); SILVEIRA, D. T. (org.). Métodos de Pesquisa. Porto Alegre: Editora da UFRGS, 2009. Disponível em:< http:// www.ufrgs.br/cursopgdr/downloadsSerie/derad005.pdf>. Acesso em: 20 fev. 2017. ISBN 978-85-386-0071-8

HACKENHAAR, I.C; WASKO, R.P.; TUBINO, R.; PASSUELLO, A. Life Cycle Assessment applied to construction and demolition waste treatment: proposal of a Brazilian scenario. IOP Conference Series: Earth and Environmental Science, Volume 323, conference 1, 2019. https://doi.org/10.1088/1755-1315/323/1/012054

IBGE. INSTITUTO BRASILEIRO DE GEOGRAFIA E ESTATÍSTICA. Sinopse do censo demográfico 2010: São Paulo. Disponível em: <http://www.censo2010.ibge.gov.br/sinopse/index.php?u$\mathrm{f}=35 \&$ dados $=0>$ acesso em 22 abr. $2016 \mathrm{a}$.

IBGE. INSTITUTO BRASILEIRO DE GEOGRAFIA E ESTATÍSTICA. Pesquisa Anual da Indústria da Construção: São Paulo. <Disponível em: < http://questionarios.ibge.gov.br/downloads-questionarios/ paic-pesquisa-anual-da-industria-da-construcao.html> acesso em 22 de out. 2016b.

IPEA. INSTITUTO DE PESQUISAS ECONÔMICAS APLICADAS. Diagnóstico de Resíduos Sólidos da Construção Civil. Brasília, 2012. Disponível em:< http://agencia.ipea.gov.br/images/stories/PDFs/ relatoriopesquisa/120911_relatorio_construcao_civil.pdf>. Acesso em 01 mai. 2017.

JÚNIOR, N. S. A., SILVA, G. A.O., DIAS, C. M.R., Ribeiro, D. V. Concrete containing recycled aggregates: Estimated lifetime using chloride migration test. Construction and Building Materials, v. 222, p. 108-118, 2019. https://doi.org/10.1016/j. conbuildmat.2019.06.136

KERN, A. P. et al. Waste generated in high-rise buildings construction : A quantification model based on statistical multiple regression. Waste Management, v. 39, p. 35-44, 2015. https://doi. org/10.1016/j.wasman.2015.01.043

KOFOWOROLA, O. F.; GHEEWALA, S. H. Estimation of construction waste generation and management in Thailand. Waste Management, v. 29, n. 2, p. 731-738, 2009. https://doi.org/10.1016/j. wasman.2008.07.004

KUSUNIKI L., GOBBI E.F., CHARVET P. Challenges in Reducing Construction and Demolition Waste Generation in Construction Sites in Curitiba. In: Leal Filho W., Borges de Brito P., Frankenberger F. (eds) International Business, Trade and Institutional Sustainability. World Sustainability Series. Springer, 2020. ISBN 9783-030-26759-9 (eBook). https://doi.org/10.1007/978-3-03026759-9

LAGE, I. M., ABELLA, F.M., VÁZQQUEZ-HERRERO, C., PÉREZ, J.L. Estimation of the annual production and composition of $C \& D$ Debris 
in Galicia (Spain). Waste Management, v. 30, n. 4, p. 636-645, 2010. https://doi.org/10.1016 j.wasman.2009.11.016

LIMA, A. S.; CABRAL, A. E. B. Caracterização e classificação dos resíduos de construção civil da cidade de Fortaleza (CE). Eng. Sanit. Ambient., Rio de Janeiro, v. 18, n. 2, p. 169-176, 2013. https://doi. org/10.1590/S1413-41522013000200009

LOCH, P., STOCKER, S. M., BERTOLINI, G. R. F. Civil construction waste management plan: a systematic review of the Brazilian scientific production from 2003 to 2016. Gestão Ambiental e Sustentabilidade, v.8, n.1, p. 100-122, 2019. https://www. semanticscholar.org/paper/CIVIL-CONSTRUCTION-WASTE-MANAGEMENT-PLAN-\%3A-A-REVIEW-Loch-Stocker/ca82ad111363fb55dd7a919ce85e11f7b1a13608.

MALIA, M.; BRITO, J.; BRAVO, M. Indicadores de resíduos de construção e demolição para construções residenciais novas. Ambient. constr. (Online), Porto Alegre, v. 11, n. 3, p. 117-130, Sept. 2011. https://doi.org/10.1590/S1678-86212011000300009

MARQUES NETO, J. C. Estudo da gestão municipal dos resíduos de construção e demolição na bacia hidrográfica do Turvo Grande (UGRHI-15). Tese (Doutorado em Ciências da Engenharia Ambiental) - Escola de Engenharia de São Carlos da Universidade de São Paulo, USP, 2009.

MENEGAKI, M., DAMIGOS, D. A review on current situation and challenges of construction and demolition waste management. Curr. Opin. Green Sustain. Chem. 13, 8 e15, 2018. https://doi. org/10.1016/j.cogsc.2018.02.010

PAZ, D.H.F, LAFAYETTE, K.P.V., SOBRAL, C. GIS-based planning for managing the flow of construction and demolition waste in Brazil. Waste Management \& Research, v. 36 (6), p. 541-549, 2018. https://doi.org/10.1177/0734242X18772096

PAZ, D.H.F, LAFAYETTE, K.P.V. Forecasting of construction and demolition waste in Brazil. Waste Management \& Research, v. 34 (8), p. 708-716, 2016. https://doi.org/10.1177/0734242X16644680
PINTO, T. P. Metodologia para a gestão diferenciada de resíduos sólidos da construção urbana. Tese (Doutorado em Engenharia de Construção Civil). Escola Politécnica da Universidade de São Paulo, São Paulo, 1999.

ROSADO, L. P., VITALE, P., PENTEADO, C. S. G., ARENA, U. Life cycle assessment of construction and demolition waste management in a large area of São Paulo State, Brazil. Waste Management, v. 85, p. 477-489, 2019. https://doi.org/10.1016/j.wasman.2019.01.011

SAMPAIO, R. J., OLIVEIRA, J. S. Ecopoints: a strategy for reducing the impacts generated by waste construction in Vitoria da Conquista City (BA). Revista Ibero-Americana de Ciências Ambientais, v.6 - n.2 p. 227-245, 2015. https://doi.org/10.6008/ SPC2179-6858.2015.002.0016

SÃO PAULO (Estado). Secretaria do Meio Ambiente. Plano de resíduos sólidos do estado de São Paulo [recurso eletrônico] / Secretaria do Meio Ambiente do Estado de São Paulo, Coordenadoria de Planejamento Ambiental, CETESB - 1a ed. - São Paulo: SMA, 2014.

Secretaria do Meio Ambiente; SINDUSCON/SP. Resíduos da Construção Civil e o Estado de São Paulo. São Paulo, SMA/SINDUSCON, 2012.84p.

SUBRAMANIAN, A.; COUTINHO, A. S.; SILVA, L. B. Aplicação de método e técnica multivariados para previsão de variáveis termoambientais e perceptivas. Produção UFPB, v. 17, n. Produção, p. 52-70, 2007. https://doi.org/10.1590/S010365132007000100004

WANG, X., ZHENG, L., WU, H., DUAN, H., WANG, J. Quantity and Treatment Status of C\&D Waste in China: BIM Application and Offsite Construction. In: 2016 International Conference on Construction and Real Estate Management, 2016. pp. 624-630. Anais...

WU, Z. et al. Quantifying construction and demolition waste: An analytical review. Waste Management, v. 34, n. 9, p. 1683-1692, 2014. https://doi.org/10.1016/j.wasman.2014.05.010 